\title{
FERRAMENTAS DE GESTÃO DE ESTOQUES NO VAREJO CALÇADISTA: UM ESTUDO SOB A ÓTICA DA PESQUISA BIBLIOGRÁFICA
}

\author{
Carolina Pires Santos, Michelle Borges Rodrigues da Silva, José Carlos do Nascimento, Sonia Sanae \\ Sato
}

Universidade do Oeste Paulista - UNOESTE, Presidente Prudente, SP. E-mail: carolina pires.stos@hotmail.com; michelleborgesadm@hotmail.com; sonia@unoeste.br

\section{RESUMO}

A gestão de estoques tornou-se essencial para o desempenho eficaz das empresas, pois permite a estas maximizar os recursos disponíveis por meio de suas ferramentas. Neste sentido, esse estudo teve como objetivo analisar as ferramentas de gestão de estoques utilizadas pelas empresas de varejo calçadista no período 2013-2017. A metodologia utilizada foi a pesquisa bibliográfica, descritiva e quantitativa. Como resultado, foi possível identificar que as pesquisas realizadas apresentaram as seguintes ferramentas para a realização da gestão de estoques nas empresas: Estoque de Segurança, Lote Econômico de Compra (LEC), Estoque Máximo, Ponto de Ressuprimento, Inventários, Ponto de Equilíbrio, Curva $A B C$ e Just-in-Time. Sendo a Curva $A B C$ e o LEC as mais citadas pelos autores.

Palavras-chaves: Estoques. Gestão de Estoques. Varejo. Varejo Calçadista.

\section{INTRODUÇÃO}

Desde a origem dos tempos já existiam atividades que podem ser entendidas como gestão de estoques. O ser humano sempre possuiu uma necessidade de produzir, estocar e trocar materiais. Nas sociedades primitivas os homens das cavernas, que eram responsáveis pela caça, precisavam saber a quantidade necessária de alimento para si e para seus familiares. Nas primeiras civilizações surgiu o escambo, pois havia a necessidade de trocar os excedentes provenientes da caça e das colheitas da agricultura familiar. Com o passar dos anos surgiram as unidades monetárias para as trocas mercantis e, devido a isso, o comércio foi se aprimorando.

No período da Idade Média a produção era totalmente artesanal e o consumo dos produtos era imediato. Somente com o advento da Revolução Industrial que a gestão de estoques mostrou-se importante, pois o modelo de fabricação artesanal foi substituído pela produção em massa em fábricas e indústrias, dessa forma, houve mais do que nunca a necessidade de armazenagens de estoques, tanto de matérias-primas quando de produtos acabados. A partir do período pós-industrial, a gestão de estoques passou a ser vista e estudada como ciência, e surgiram conceitos, métodos e ferramentas que aperfeiçoaram as atividades empresariais.

Atualmente, a gestão de estoques é primordial para o bom funcionamento das empresas, e ela tornou-se também essencial para o comércio varejista, como por exemplo, para as lojas de calçados, que enfrentam problemas com a disponibilidade de produtos e com níveis de estoques. As ferramentas de gestão de estoques aperfeiçoam os processos empresariais, contribuem para um melhor retorno do investimento e garantem a disponibilidade de produtos aos clientes; enquanto a ausência dessas ferramentas causa sérios prejuízos às organizações.

Neste contexto, a presente pesquisa teve como objetivo analisar as ferramentas de gestão de estoques utilizadas pelas empresas de varejo calçadista no período 2013-2017. Esse estudo se justifica por buscar entender quais ferramentas são mais utilizadas pelas empresas de calçados e quais as contribuições geradas pela aplicação destas, beneficiando a todos os proprietários de empresas de calçados, funcionários e futuros empreendedores do ramo. 


\section{METODOLOGIA}

Para elaboração e desenvolvimento desta pesquisa, os procedimentos adotados dividiramse em três etapas: 1) revisão bibliográfica, visando o desenvolvimento do referencial teórico; 2 ) pesquisa bibliográfica realizada no Google Acadêmico; 3) Coleta de dados e análise de resultados.

A etapa inicial desta pesquisa foi a revisão bibliográfica, na qual se procurou conhecimentos relacionadas às ferramentas de gestão de estoques, baseando-se em estudos de autores reconhecidos como Arnold (2014), Slack (2009) e Martins (2000), os quais contribuíram com suas teorias para o desenvolvimento das ferramentas mencionadas neste trabalho.

Na segunda etapa foi realizada entre julho e agosto de 2017, uma pesquisa bibliográfica baseada na literatura especializada através de consulta a artigos científicos selecionados através de busca no banco de dados do Google Acadêmico, sendo que a busca neste banco de dados foi realizada utilizando as palavras-chave Gestão de Estoques e Varejo Calçadista. O setor escolhido foi o varejo calçadista, pois é uma área na qual as autoras já vêm realizando pesquisas.

Por fim, os dados coletados foram analisados com o objetivo de se identificar e compreender as ferramentas de gestão de estoques mais empregadas nos estudos encontrados.

Assim, considerando o exposto, esta pesquisa classifica-se como bibliográfica, que de acordo com Köche (2009, p.122) é aquela que tem como objetivo "[...] conhecer e analisar as principais contribuições teóricas existentes sobre um determinado tema ou problema, tornandose um instrumento indispensável para qualquer tipo de pesquisa". Ela também tem caráter descritivo, pois busca abordar as principais ferramentas de gestão de estoques utilizadas pelas empresas e que segundo Cervo, Bervian e Silva (2007, p. 61) trata-se de uma pesquisa que

[...] observa, registra, analisa e correlaciona fatos [...] sem manipulá-los. Procura descobrir, com maior precisão possível, a frequência com que um fenômeno ocorre, [...]. Busca conhecer as diversas situações e relações que ocorrem na vida social, política, econômica, e demais aspectos do comportamento humano, tanto no individuo tomado isoladamente como de grupos e comunidades mais complexas.

E esta pesquisa classifica-se ainda como quantitativa, uma vez que os dados coletados e utilizados para o desenvolvimento do seu tema foram oriundos da pesquisa bibliográfica. A esse respeito Casarin $(2012$, p. 36) comenta que a pesquisa quantitativa "[...] procura, entre outras coisas, avaliar o comportamento de uma variável analisando a frequência com que ela ocorre. A partir da análise dos resultados, busca explicações ou soluções que esclareçam o fenômeno observado".

\section{FUNDAMENTOS DA GESTÃO DE ESTOQUES}

Toda empresa possui produtos em estoque, desde os pequenos comércios às grandes indústrias. Segundo Chiavenato (2014, p. 90) "estoque é a composição de materiais [...] que não é utilizada em determinado momento na empresa, mas que precisa existir em função de futuras necessidades". Ou seja, os estoques são uma forma de garantia de disponibilidade de recursos para as empresas, sejam para venda ao consumidor ou para utilização em seus processos internos.

O estoque desenvolve um papel relevante dentro das empresas, principalmente no que diz respeito à satisfação dos clientes. Segundo Martins $(2000,133)$ "[...] a oportunidade de atendê-los prontamente, no momento e na quantidade desejada, é grandemente facilitada com a administração eficaz dos estoques". E isto faz com que o cliente no momento de sua compra retorne a empresa, devido à agilidade do atendimento.

Outra vantagem observada nas empresas que praticam a gestão de estoques é um aumento na lucratividade. "Em termos financeiros, os estoques são muito importantes para as empresas [...]. À medida que os estoques vão sendo utilizados, seu valor se converte em dinheiro, 
o que melhora o fluxo de caixa e o retorno sobre o investimento" (ARNOLD, 2014, p. 247). Logo, as empresas que exercem um controle eficiente dos seus estoques alcançam melhores resultados sobre suas aplicações.

Observando a importância dos estoques para as organizações, entende-se a necessidade da gestão eficaz desses recursos. De acordo com Martins (2000, p.155) "[...] gestão de estoques constitui uma série de ações que permitem ao administrador verificar se os estoques estão sendo bem utilizados, bem localizados em relação aos setores que deles se utilizam, bem manuseados e controlados". Por conseguinte, a gestão de estoques facilita a administração dos recursos e aumenta a eficiência dos processos empresariais.

Embora existam inúmeros benefícios, todo acúmulo de estoques gera custos para as empresas. Esses custos podem ser classificados como diretos ou indiretos e levam em consideração a quantidade de produtos em estoque e o tempo que permanecerão estocados. Os custos podem ser agrupados em custos de capital, custos com pessoal, custos com edificação e custos de manutenção (DIAS, 2011).

O conjunto dos custos relativos aos estoques são chamados de custos de armazenagem. Conforme menciona Slack, Chambers e Johnston (2009, p. 363) "esses são os custos associados a armazenagem física dos bens. Locação, climatização e iluminação do armazém, assim como seu seguro [...]". Em virtude disso, pode-se concluir que esses custos são proporcionais a quantidade e ao tempo de permanência em estoque e são calculados por meio do custo médio ponderado dos produtos.

Paralelamente, as empresas possuem custos relacionados ao pedido, que segundo Ching (2010, p. 14) "incluem os custos fixos administrativos associados ao processo de aquisição das quantidades requeridas para reposição de estoque." Ou seja, tratam-se de custos relacionados a todo o processo burocrático realizado para a obtenção de materiais.

Além disso, há o custo ocasionado pela falta de estoque, o mesmo ocorre quando o consumidor busca por "[...] determinado produto e ele não está disponível no estoque ou então ele chega atrasado. Com isso, o cliente tanto pode desistir da compra como pode até comprar, mas sua insatisfação pode gerar perdas de vendas futuras" (CASTIGLIONI, 2014, p. 36). A vista disso, percebe-se que é crucial evitar indisponibilidade de produtos através da gestão eficaz de estoques, que pode ser realizada tendo como referência o custo total de se manter estoques.

O custo total é o principal indicador utilizado pelas organizações para medir seus dispêndios em relação aos estoques. De acordo com Dias (2011, p. 39) "o Custo Total é o somatório do Custo de armazenagem e do Custo de pedido". Dessa forma, ele fornece um índice geral do que está sendo gasto no processo de estocagem, por isso recebe muita atenção da gestão de estoques, que objetiva minimizá-lo sempre.

Um dos desafios encontrados no âmbito da gestão de estoques é a forma de avaliar os custos dos materiais que os compõem. "A avaliação de estoque exerce influência direta nos custos, tanto de matérias-primas, quanto de produtos" (ZORZO, 2015, p. 26). Por esse motivo, é essencial conhecer a quantidade de itens disponíveis e seu respectivo valor econômico.

\section{FERRAMENTAS DA GESTÃO DE ESTOQUES}

Existem algumas ferramentas para a realização da avaliação de estoques, sendo essas três bastante conhecidas: Primeiro a Entrar, Primeiro a Sair (PEPS), Último a Entrar, Primeiro a sair (UEPS) e Custo Médio. O PEPS obedece a uma ordem cronológica e determina que os produtos mais antigos sejam vendidos com prioridade e com preços atuais, gerando um lucro bruto maior para a empresa (MEGLIORINI, 2011).

O UEPS é muito utilizado em períodos de alta inflação, pois estabelece que os últimos produtos adquiridos sejam os primeiros a deixarem o estoque, dessa forma os custos são calculados de acordo com as entradas mais recentes (MEGLIORINI, 2011). 
Já no método Custo Médio, é feita uma média ponderada entre os custos de aquisição dos lotes de cada produto em estoque, resultando em um valor unitário geral e mantendo o estoque equilibrado em longo prazo. Essa ferramenta pode ser dividida em Custo Médio Ponderado Móvel, em que a saída dos produtos é registrada assim que ocorre a venda, e Custo Médio Ponderado Fixo, no qual o material vendido é baixado do sistema apenas ao fim do mês, independente do dia em que foi vendido (SCHIER, 2013).

Há também as ferramentas próprias da gestão de estoques, entre as quais destacam-se: o Lote Econômico de Compra (LEC) ou Lote Econômico de Fabricação (LEF), a Curva ABC, o Estoque de Segurança, o Estoque Máximo, o Ponto de Equilíbrio, o Ponto de Ressuprimento, o Just in time e o Inventário.

O LEC se refere a quantidade ideal de material a ser adquirida em cada operação de reposição de estoques de uma empresa. Segundo Lélis (2016 p.96) "Para tomar essa decisão é preciso levar em conta a disponibilidade de recurso financeiro, a área de armazenagem e o custo do suprimento". Essa ferramenta permite ao empresário identificar se é vantajoso ou não para a empresa estocar, e caso seja, qual o volume necessário. Sendo assim, evita com que a empresa compre lotes de mercadorias menores ou maiores do que o necessário para aquele momento.

Já a Curva $A B C$ baseia-se em avaliar em grau de importância quais são os itens que devem receber mais atenção a partir do seu valor para a empresa. Segundo Lélis, $(2016$, p.67) "Essa análise consiste em verificar, dentro de um determinado espaço de tempo, em valor monetário ou quantidade, os itens em estoque, classificando-os em ordem de importância". Sob esse prisma, os itens mais importantes de todos são chamados itens classe $A$, aos intermediários denomina-se itens classe $B$, e aos menos importantes chama-se itens classe $C$.

De acordo com estudos realizados por Dias (2011, p.73):

Após os itens terem sido ordenados pela importância relativa, as classes da curva $A B C$ podem ser definidas das seguintes maneiras:

- Classe A: Grupo de itens mais importantes que devem ser tratados com uma atenção bem especial pela administração.

- Classe B: Grupo de itens em situação intermediária entre as classes A e $C$.

- Classe C: Grupo de itens menos importantes que justificam pouca atenção por parte da administração.

Sendo assim, é possível identificar a importância de cada classe, possibilitando ao gestor da empresa identificar quais produtos devem ser comprados com maior frequência ou quantidade, e detectar aqueles que devem ser comprados em quantidades menores devido à pequena saída de vendas. Assim, é possível se observar algumas vantagens quanto ao uso da Curva $A B C$, tal como evitar os desperdícios por mercadorias que não foram vendidas e diminuição das perdas de produtos estocados por muito tempo, ocasionando uma diminuição no desperdício de capital e gerando maior lucratividade para a empresa.

O Estoque de Segurança é uma ferramenta empregada pelas empresas para evitar a indisponibilidade de produtos aos clientes. Chiavenato(2014, p. 91) afirma que "sua função é proteger o sistema produtivo quando a demanda (D) e o tempo de reposição (L) variam ao longo do tempo."Ou seja, as empresas mantêm o Estoque de Segurança para se proteger das incertezas relacionadas à demanda e ao tempo de ressuprimento.

Outra ferramenta que trabalha com níveis de estoques é chamada de Estoque máximo. "Estoque máximo (Emáx) é a quantidade equivalente à soma do estoque mínimo com a reposição do lote de compra." (CHIAVENATO, 2014,p. 106). Isto é, se refere à quantidade máxima que podese existir em estoques, geralmente, as empresas empregam esta ferramenta como uma forma de alerta para possíveis perdas futuras. 
O Ponto de equilíbrio "define a quantidade (q) de produção necessária para que o custo total (CT) seja igual ao faturamento. Ele representa a quantidade que devemos produzir para que a unidade produtiva deixe de ter prejuízo"(ALBERTIN, 2016, p. 57). Na gestão de estoques o Ponto de Equilíbrio é usado para adequar as quantidades de estoques em relação ao capital de giro da empresa.

Há também o Just in time (JIT) que de acordo com Fenerich(2016, p. 156)"[...] é uma filosofia avessa à abordagem tradicional da manufatura e contribui em diversos aspectos para as operações realizadas no processo, principalmente no que se refere à satisfação do consumidor e aos custos operacionais." Ainda de acordo com o autor, quando se relaciona o just in time com a gestão de estoques, percebe-se que quanto maior o nível de estoques, mais problemas podem estar sendo mascarados na empresa, enquanto uma menor quantidade de estoques permite à organização visualizar melhor seus pontos negativos e assim, podem buscar soluções.

Além destas ferramentas há o Ponto de ressuprimento, que conforme menciona Suzano (2013, p. 156) "é a quantidade de material predeterminada que, a ser atingida pela ação do consumo, dá origem a uma solicitação de ressuprimento. Também tratado como nível de reposição e ponto de reposição." Ou seja, é preciso que a empresa estabeleça um nível de estoques, que ao ser atingido, gere um requerimento de compra e garanta a disponibilidade de produtos enquanto se aguarda a chegada do próximo lote.

E, por fim, o inventário que "pode ser visto como a contagem física dos itens. Se depois da contagem efetuada a quantidade física não estiver de acordo com a quantidade contábil, serão necessários ajustes de estoque e fiscais." (LÉLIS, 2016, p. 72). Sendo assim, o inventário é uma das mais relevantes ferramentas, mas deve ser aplicada com prudência para que não ocorram divergências.

\section{RESULTADOS E DISCUSSÃO}

Para alcançar o objetivo geral deste estudo foi necessária a utilização da pesquisa bibliográfica como fonte de coleta de dados, sendo que a mesma foi fundamentada na investigação dos artigos publicados no Google Acadêmico.

Utilizando exatamente as palavras gestão de estoques e varejo calçadista, foram encontrados precisamente 4.090 resultados.

Empregando uma classificação desde 2013 e pesquisando somente nas páginas em português, foram encontrados 1.150 artigos que versavam sobre estoques sob diversos ângulos, como avaliação, controle, custos, gestão, entre outros, varejo e setor calçadista. Além disso, os resultados também abordavam vários assuntos relacionados às palavras-chave pesquisadas, que não eram compatíveis com o tema deste estudo.

Após a leitura do resumo dos 1.150 artigos, foram selecionados 4 artigos que versavam sobre estoques no setor de varejo calçadista em empresas de pequeno porte.

Em seguida, foi realizada a análise dos4 artigos. Os autores Morais e Souza, que realizaram um estudo de caso na Sapataria Muniz no Shopping Difusora de Caruaru/PE, afirmam que as ferramentas mais utilizadas na gestão de estoques de lojas de calçados são: Curva ABC, LEC e Justin-time. O que iguala ao apresentado por Fenerich (2016), que também reconhece os benefícios gerados pelo uso destas ferramentas.

Já os autores Gomes e Nogueira, em sua pesquisa caracterizada como levantamento, afirmaram que o inventário é a ferramenta mais utilizada,o que iguala ao apresentado por Lélis (2016), que considera o inventário uma ferramenta essencial para a gestão de estoques.

Alves Junior, em seus estudos de Análise Multivariada, apresentou as ferramentas: LEC, Estoque Máximo e Ponto de Ressuprimento, o que difere ao apresentado por Slack (2009), que apresenta outras ferramentas como fundamentais para a gestão de estoques. 
Nos estudos de Schafer, caracterizado como bibliográfico e documental, foram encontradas as ferramentas Curva $A B C$ e Análise do Ponto de Equilíbrio. O que iguala ao apresentado por Albertin (2016), que também traz essas ferramentas.

\section{CONCLUSÃO}

Foi possível verificar que a gestão de estoques identificada pelos 4 artigos analisados envolveu a utilização das seguintes ferramentas: Estoque de Segurança, LEC, Estoque Máximo, Ponto de Ressuprimento, Inventários, Ponto de Equilíbrio, Curva $A B C$ e Just-in-Time.

Identificou-se que as ferramentas Curva $A B C$ e LEC, foram as mais citadas pelos autores, ambas com a mesma frequência.

Outro fator verificado, é que as ferramentas elas auxiliam os proprietários na gestão do estoque, diminuindo-se as perdas, aumentando-se o lucro, reduzindo o excesso de estoques e até mesmo evitando com que faltem mercadorias nas empresas, sendo que elas auxiliam o proprietário para tomar a decisão correta.

\section{REFERÊNCIAS BIBLIOGRÁFICAS}

ALBERTIN, M. R. Administração da produção e operações. Curitiba: InterSaberes, 2016.

ARNOLD, J. R. T. Administração de materiais: uma introdução. São Paulo: Atlas, 2014.

CASARIN, H. C. S. Pesquisa científica: da teoria à pratica. Curitiba: InterSaberes, 2012.

CASTIGLIONI, J. A. M. Custos de processos logísticos. São Paulo: Érica, 2014.

CERVO, A. L.; BERVIAN, P. A.; SILVA, R. Metodologia científica. 6 ed. São Paulo: Pearson Prentice Hall, 2007.

CHIAVENATO, I. Gestão de materiais: uma abordagem introdutória. 3 ed. Barueri: Manole, 2014.

CHING H. Y. Gestão de estoques na cadeia de logística integrada. 4 ed. São paulo: Atlas, 2010.

DIAS, M. A. P. Administração de materiais: princípios, conceitos e gestão. 6 ed. São Paulo: Atlas, 2011.

FENERICH, F. C. Administração dos sistemas de operações. Curitiba: InterSaberes, 2016.

KÖCHE, J. C. Fundamentos da metodologia científica: teoria da ciência e iniciação à pesquisa. 28 ed. Petrópolis: Vozes, 2009.

LÉLIS, E. C. Administração de materiais. São Paulo: Pearson Education do Brasil, 2016.

MARTINS, P. G.; ALT, P. R. C. Administração de materiais e recursos patrimoniais. São Paulo: Saraiva, 2000.

SLACK, N.;CHAMBERS S.; JOHNSTON R. Administração da produção. 3 ed. São Paulo: Atlas, 2009.

SUZANO, M. A. Administração da produção e operações com ênfase em logística. Rio de janeiro: Interciência, 2013. 
ZORZO, A. Gestão de produtos e operações. São Paulo: Pearson Education do Brasil, 2015.

LÉLIS, E. C. Administração de materiais. São Paulo: Pearson Education do Brasil, 2016. 